\title{
Diagnostic Performance of Endoscopic Ultrasound Elastography for Differential Diagnosis of Solid Pancreatic Lesions: A Propensity Score-Matched Analysis
}

In Rae Cho

Seoul National University College of Medicine

Seok-Hoo Jeong

Catholic Kwandong University International St. Mary's Hospital

Huapyong Kang

Gachon University Gil Medical Center

Eui Joo Kim

Gachon University Gil Medical Center

Yeon Suk Kim

Gachon University Gil Medical Center

Soyoung Jeon

Yonsei University College of Medicine

Jae Hee Cho ( $\nabla$ jhcho9328@gmail.com )

Yonsei University College of Medicine

Research Article

Keywords:

Posted Date: February 17th, 2022

DOI: https://doi.org/10.21203/rs.3.rs-1319504/v1

License: (c) (i) This work is licensed under a Creative Commons Attribution 4.0 International License. Read Full License 


\section{Abstract \\ Background}

Endoscopic ultrasound-elastography (EUS-EG) is a non-invasive complementary diagnostic method for the differential diagnosis of solid pancreatic lesions (SPL). However, the optimal strain ratio (SR) value and diagnostic performance of EUS-EG have not yet been determined in pancreatic neuroendocrine neoplasm (PNEN), mass-forming pancreatitis (MFP), and pancreatic ductal adenocarcinoma (PDAC). We aimed to determine the optimal SR value in EUS-EG for differential diagnosis of SPLs.

\section{Methods}

A total 134 patients who underwent EUS-EG to evaluate SPL were retrospectively investigated. Patients were divided into 3 groups - PNEN $(n=10), \operatorname{MFP}(n=37)$, and PDAC $(n=87)$. Baseline characteristics and results of EUS-EG were compared between groups and statistical analyses were performed for differential diagnosis.

\section{Results}

The mean SR values of each group were 11.85 \pm 7.56 (PNEN), 11.45 \pm 5.97 (MFP), and $22.50 \pm 13.19$ (PDAC), respectively. There was significant association between $S R$ value increase and PDAC diagnosis (PNEN versus PDAC, $p=0.0216$; MFP versus PDAC, $p=0.0006$ ) in multinomial logistic regression analysis. $S R$ value of 17.14 was confirmed as the optimal cut-off value for differential diagnosis between MFP and PDAC.

\section{Conclusions}

Differential diagnosis of SPL could be performed using EUS-EG. The cut-off SR value presented in this study is expected to be useful in differential diagnosis.

\section{Clinical trial registration number:}

https://cris.nih.go.kr/cris : KCT0002082

\section{Introduction}

Endoscopic ultrasound (EUS) has become an essential tool for the investigation of pancreatic diseases. EUS provides high-resolution images and safely enables tissue imaging acquisition. However, the differential diagnosis of solid pancreatic lesions (SPLs), especially pancreatic neuroendocrine neoplasm (PNEN), mass forming pancreatitis (MFP), and pancreatic ductal adenocarcinoma (PDAC), remains a 
clinical challenge. When diagnosing a malignant SPL using EUS-FNA, a negative predictive value (NPV) of $46-80 \%$ has been reported. This was also associated with a low but not ignorable risk of complications. ${ }^{1,2}$

Recently, various efforts have been made to improve the diagnostic yield of EUS for SPL through innovative and non-invasive methods that analyze the characteristics of the SPL (internal vascularity, stiffness, or perfusion). ${ }^{3-5}$ EUS-elastography (EUS-EG) is a non-invasive diagnostic method based on the measurement of tissue stiffness. ${ }^{6}$ When pressure induced by the transducer or small vessel movements is applied to a given tissue, structural deformation (strain) occurs. Strain varies according to tissue stiffness. EUS-EG describes tissue stiffness in color scales. Soft tissue that presents a large strain is expressed as red color, while hard tissue with a smaller strain is expressed as blue. ${ }^{7}$

EUS-EG and semi-quantitative evaluation of the strain ratio (SR) has been used in the differential diagnosis of SPL. ${ }^{4,8,9} \mathrm{SR}$ is calculated as the ratio of the mean strain in a region of interest (ROI) within the SPL and a reference area that is usually selected from the adjacent gut wall. This semi-quantitative evaluation can compensate for the shortcomings of qualitative evaluation using color patterns and diminishes interobserver differences. ${ }^{8}$ In previous studies, several SR values for differential diagnosis had been suggested. ${ }^{10,11}$ However, since cut-off values vary between different studies, the optimal cut-off and reference range SR values for diagnosis using EUS-EG have not yet been determined. This study aimed to evaluate the impact of EUS-EG for the diagnosis of SPLs, including MFP, PNEN, and PDAC.

\section{Results}

\section{Patients' characteristics}

During the study period, 221 patients had undergone EUS-EG for SPL. Among them, 134 patients, whose SR value could be identified on the EUS images and could be described, were included in the study and were analyzed. The baseline characteristics of all the patients are summarized in Table 1 . The mean patient age was $62.4 \pm 13.4$ years. The mean size of the SPL and mean SR were $31.4 \pm 14.2 \mathrm{~mm}$ and $18.65 \pm 12.40$, respectively. Ten (7.5\%) patients had PNEN, 37 (27.6\%) patients had MFP, and 87 (64.9\%) patients were diagnosed with PDAC. 
Table 1

Baseline characteristics

\begin{tabular}{|c|c|c|c|c|}
\hline \multirow[t]{2}{*}{ Variable } & All patient & PNEN & MFP & PDAC \\
\hline & $(n=134)$ & $(n=10)$ & $(n=37)$ & $(n=87)$ \\
\hline Age & $62.4( \pm 13.4)$ & $61.6( \pm 13.5)$ & $54.7( \pm 12.1)$ & $65.8( \pm 12.7)$ \\
\hline \multicolumn{5}{|l|}{ Sex } \\
\hline Male & $79(59.0)$ & $6(60.0)$ & $29(78.4)$ & $44(50.6)$ \\
\hline Female & $55(41.0)$ & $4(40.0)$ & $8(21.6)$ & $43(49.4)$ \\
\hline Size of lesion (mm) & $31.4( \pm 14.2)$ & $24.8 \pm(16.4)$ & $28.2( \pm 9.5)$ & $33.5( \pm 15.2)$ \\
\hline \multicolumn{5}{|l|}{ Location } \\
\hline Body-Tail & $62(46.3)$ & $7(70.0)$ & $12(32.4)$ & $43(49.4)$ \\
\hline Head & $72(53.7)$ & $3(30.0)$ & $25(67.6)$ & $44(50.6)$ \\
\hline \multicolumn{5}{|l|}{ Elastography_Color } \\
\hline Green & $18(13.4)$ & $4(40.0)$ & $11(29.7)$ & $3(3.4)$ \\
\hline Blue & $116(86.6)$ & $6(60.0)$ & $26(70.3)$ & $84(96.6)$ \\
\hline \multicolumn{5}{|l|}{ Elastography_Pattern } \\
\hline Homogeneous & $10(7.5)$ & $5(50.0)$ & $2(5.4)$ & $3(3.4)$ \\
\hline Heterogenous & $124(92.5)$ & $5(50.0)$ & $35(94.6)$ & $84(96.6)$ \\
\hline SR value & $18.65( \pm 12.40)$ & $11.85( \pm 7.56)$ & $11.45( \pm 5.97)$ & $22.50( \pm 13.19)$ \\
\hline \multicolumn{5}{|c|}{ Values are expressed as mean $( \pm S D)$ or $n(\%)$} \\
\hline $\begin{array}{l}\text { Abbreviations: PNEI } \\
\text { pancreatic ductal ac }\end{array}$ & $\begin{array}{l}\text { atic neuroendo } \\
\text { inoma; SR, stra }\end{array}$ & $\begin{array}{l}\text { neoplasm; M } \\
\text { io. }\end{array}$ & ass-forming $p$ & eatitis; PDAC, \\
\hline
\end{tabular}

\section{Variables associated with PDAC}

Multinomial logistic regression analysis was performed to confirm whether there were differences in measured variables between groups (Table 2). When comparing the PNEN group with the MFP and PDAC groups, a heterogeneous pattern of elastography was significantly associated with MFP and PDAC $(p=0.0142$ and 0.0007 , respectively). An increase in SR was significantly associated with PDAC when compared with the PNEN group (odds ratio [OR] 1.265, 95\% $\mathrm{Cl} 1.035-1.546 ; \mathrm{p}=0.0216$ ). When comparing MFP group and PDAC group, older age (OR 1.060, 95\% Cl 1.018-1.103; $p=0.0045)$, increase of SR (OR $1.184,95 \% \mathrm{Cl} 1.075-1.305 ; p=0.0006)$, and female sex (OR 3.448, 95\% $\mathrm{Cl} 1.107-10.738 ; p=0.0327$ ) were significantly associated with PDAC. 
Table 2

Multinomial logistic regression analysis

\begin{tabular}{|c|c|c|c|c|c|c|}
\hline \multirow[t]{2}{*}{ Variables } & \multicolumn{2}{|c|}{ PNEN (ref) vs MFP } & \multicolumn{2}{|c|}{ PNEN (ref) vs PDAC } & \multicolumn{2}{|c|}{ PNEN (ref) vs PDAC } \\
\hline & $\begin{array}{l}\mathrm{OR}(95 \% \\
\mathrm{Cl})\end{array}$ & $\mathbf{P}$ & $\begin{array}{l}\mathrm{OR}(95 \% \\
\mathrm{Cl})\end{array}$ & $P$ & OR(95\% Cl) & $P$ \\
\hline Age & $\begin{array}{l}0.952 \\
(0.889- \\
1.021)\end{array}$ & 0.1669 & $\begin{array}{l}1.010 \\
(0.941- \\
1.083)\end{array}$ & 0.7897 & $\begin{array}{l}1.060(1.018- \\
1.103)\end{array}$ & 0.0045 \\
\hline \multicolumn{7}{|l|}{ Sex } \\
\hline Male & ref & & ref & & ref & \\
\hline Female & $\begin{array}{l}0.783 \\
(0.104- \\
5.883)\end{array}$ & 0.8125 & $\begin{array}{l}2.701 \\
(0.369- \\
19.793)\end{array}$ & 0.3282 & $\begin{array}{l}3.448 \\
(1.107- \\
10.738)\end{array}$ & 0.0327 \\
\hline Size of lesion & $\begin{array}{l}1.032 \\
(0.961- \\
1.108)\end{array}$ & 0.3919 & $\begin{array}{l}1.029 \\
(0.958- \\
1.105)\end{array}$ & 0.4355 & $\begin{array}{l}0.997 \\
(0.954- \\
1.043)\end{array}$ & 0.9056 \\
\hline \multicolumn{7}{|l|}{ Location } \\
\hline Body-Tail & ref & & ref & & ref & \\
\hline Head & $\begin{array}{l}6.008 \\
(0.830- \\
43.470)\end{array}$ & 0.0758 & $\begin{array}{l}2.670 \\
(0.363- \\
19.617)\end{array}$ & 0.3346 & $\begin{array}{l}0.444 \\
(0.148- \\
1.335)\end{array}$ & 0.1484 \\
\hline \multicolumn{7}{|c|}{ Elastography_Color } \\
\hline Green & ref & & ref & & ref & \\
\hline Blue & $\begin{array}{l}0.645 \\
(0.066- \\
6.262)\end{array}$ & 0.7054 & $\begin{array}{l}1.703 \\
(0.143- \\
20.296)\end{array}$ & 0.6736 & $\begin{array}{l}2.640 \\
(0.524- \\
13.316)\end{array}$ & ‘ \\
\hline \multicolumn{7}{|c|}{ Elastography_Pattern } \\
\hline Homogeneous & ref & & ref & & ref & \\
\hline Heterogenous & $\begin{array}{l}31.042 \\
(1.995- \\
483.033)\end{array}$ & 0.0142 & $\begin{array}{l}354.746 \\
(11.858- \\
>999.999)\end{array}$ & 0.0007 & $\begin{array}{l}11.428 \\
(0.710- \\
184.046)\end{array}$ & 0.0858 \\
\hline SR value & $\begin{array}{l}1.068 \\
(0.875- \\
1.304)\end{array}$ & 0.5172 & $\begin{array}{l}1.265 \\
(1.035- \\
1.546)\end{array}$ & 0.0216 & $\begin{array}{l}1.184 \\
(1.075- \\
1.305)\end{array}$ & 0.0006 \\
\hline
\end{tabular}

The optimal cut-off SR value for differential diagnosis 
After confirming a significant association between the increase of SR and PDAC, we attempted to find the optimal cut-off SR value for differential diagnosis. After excluding the PNEN group owing to a relatively small number of patients, propensity score matching was performed to correct for heterogeneity of age, sex, size, and location of SPL between the MFP and PDAC groups. After propensity score matching, 22 patients in each group were analyzed. There were no significant differences with regard to baseline characteristics (age, sex, tumor size and location, and elastography color and pattern) between the analyzed MFP and PDAC groups (Table 3 ). Even after propensity score matching, there was a significant difference in mean SR value between the MFP and PDAC groups. (12.33 \pm 6.08 vs. $23.37 \pm 14.06 ; p=0.0019)$ (Figure 2). SR value of 17.14 was confirmed as the optimal cut-off value for differential diagnosis between MFP and PDAC. Area under the receiver operating characteristic curve was 0.760 regarding the strain ratio (17.14) for the differential diagnosis (Figure 3).

Table 3

Characteristics of MFP and PDAC group patients, after propensity score matching

\begin{tabular}{|c|c|c|c|}
\hline \multirow[t]{2}{*}{ Variables } & \multirow{2}{*}{$\begin{array}{l}\text { MFP } \\
(n=22)\end{array}$} & \multirow{2}{*}{$\begin{array}{l}\text { PDAC } \\
(n=22)\end{array}$} & \multirow[t]{2}{*}{ p-value } \\
\hline & & & \\
\hline Age & $60.6( \pm 11.4)$ & $61.4( \pm 11.5)$ & 0.5758 \\
\hline \multicolumn{3}{|l|}{ Sex } & 0.5637 \\
\hline Male & $16(72.73)$ & 17(77.27) & \\
\hline Female & $6(27.27)$ & $5(22.73)$ & \\
\hline Size of lesion & $30.0( \pm 8.6)$ & $30.8( \pm 13.5)$ & 0.77 \\
\hline \multicolumn{3}{|l|}{ Location } & $>0.999$ \\
\hline Body-Tail & $8(36.4)$ & $8(36.4)$ & \\
\hline Head & $14(63.6)$ & $14(63.6)$ & \\
\hline \multicolumn{3}{|l|}{ Elastography_Color } & 0.1025 \\
\hline Green & $6(27.3)$ & $2(9.19)$ & \\
\hline Blue & $16(72.7)$ & $20(90.9)$ & \\
\hline \multicolumn{3}{|l|}{ Elastography_Pattern } & 0.3173 \\
\hline Homogeneous & $1(4.6)$ & $0(0.00)$ & \\
\hline Heterogenous & $21(95.4)$ & $22(100.00)$ & \\
\hline SR value & $12.33( \pm 6.08)$ & $23.37( \pm 14.07)$ & 0.0019 \\
\hline \multicolumn{4}{|c|}{ Values are expressed as mean ( $\pm S D)$ or $n(\%)$} \\
\hline $\begin{array}{l}\text { Abbreviations: MFP, ma } \\
\text { ratio. }\end{array}$ & creatitis; PDA & ic ductal adenoc & $S R$, strain \\
\hline
\end{tabular}


The sensitivity, specificity, positive predictive value, negative predictive value, and accuracy of this strain ratio using cut-off value of 17.14 were $68.2 \%$ (95\% Cl: $48.7-87.7), 86.4 \%$ (95\% Cl: $72.0-99.9), 83.3 \%$ (95\% Cl: 66.1-99.9), 73.1\% (95\% Cl: 56.0-90.1), and 77.3\% (95\% Cl: 64.9-89.7), respectively. When SR cut-off values of $4.65,6.04$, and 15.41 (derived from previous studies) were used for our patients, diagnostic accuracy of PDAC were $52.3 \%, 52.3 \%$, and $77.3 \%$, respectively (Table 4). ${ }^{10,11}$

Table 4

Accuracy of SR value for the diagnosis of pancreatic cancer based on different cut-off values.

\begin{tabular}{|c|c|c|c|c|}
\hline & Present study & $\begin{array}{l}\text { Reference } 1 \\
\text { (cut-off for } \\
\text { sensitivity } \\
\text { derived from } \\
\text { Dawwas et } \\
\text { al. }^{11} \text { ) }\end{array}$ & $\begin{array}{l}\text { Reference } 2 \\
\text { (cut-off for } \\
\text { accuracy derived from Iglesias- } \\
\text { Garcia et al. }{ }^{10} \text { ) }\end{array}$ & $\begin{array}{l}\text { Reference } 3 \\
\text { (cut-off for } \\
\text { specificity } \\
\text { derived from } \\
\text { Iglesias-Garcia } \\
\text { et al. }{ }^{10} \text { ) }\end{array}$ \\
\hline $\begin{array}{l}\text { cut-off SR } \\
\text { value }\end{array}$ & 17.14 & 4.65 & 6.04 & 15.41 \\
\hline $\begin{array}{l}\text { Sensitivity } \\
(95 \% \mathrm{Cl})\end{array}$ & $\begin{array}{l}68.18(48.72- \\
87.65)\end{array}$ & $\begin{array}{l}100.00 \\
(100.00- \\
100.00)\end{array}$ & 95.45 (86.75-99.99) & $\begin{array}{l}68.18(48.72- \\
87.65)\end{array}$ \\
\hline $\begin{array}{l}\text { Specificity } \\
(95 \% \mathrm{Cl})\end{array}$ & $\begin{array}{l}86.36(72.02- \\
>99.99)\end{array}$ & $\begin{array}{l}4.55(<0.01- \\
13.25)\end{array}$ & $9.09(<0.01-21.10)$ & $\begin{array}{l}86.36(72.02- \\
99.99)\end{array}$ \\
\hline $\begin{array}{l}\text { PPV }(95 \% \\
\text { Cl) }\end{array}$ & $\begin{array}{l}83.33(66.12- \\
>99.99)\end{array}$ & $\begin{array}{l}51.16(36.22- \\
66.10)\end{array}$ & $51.22(35.92-66.52)$ & $\begin{array}{l}83.33(66.12- \\
99.99)\end{array}$ \\
\hline $\begin{array}{l}\mathrm{NPV}(95 \% \\
\mathrm{Cl})\end{array}$ & $\begin{array}{l}73.08(56.03- \\
90.13)\end{array}$ & $\begin{array}{l}100.00 \\
(100.00- \\
100.00)\end{array}$ & $66.67(13.32-99.99)$ & $\begin{array}{l}73.08(56.03- \\
90.13)\end{array}$ \\
\hline $\begin{array}{l}\text { Accuracy } \\
(95 \% \mathrm{Cl})\end{array}$ & $\begin{array}{l}77.27(64.89- \\
89.66)\end{array}$ & $\begin{array}{l}52.27(37.51- \\
67.03)\end{array}$ & $52.27(37.51-67.03)$ & $\begin{array}{l}77.27(64.89- \\
89.66)\end{array}$ \\
\hline
\end{tabular}

\section{Discussion}

In the present study, we confirmed that SR measurement through EUS-EG was useful for differential diagnosis in SPL. The SR value of PDAC patients was significantly higher than that of MFP and PNEN patients. Even after propensity-score matching, which corrects demographic difference, the SR values remained significantly different between MFP and PDAC patients. Moreover, we presented an optimal cutoff SR value that can be used for differential diagnosis of MFP and PDAC. The cut-off value presented in this study has the advantage that it is independent of demographics and shows improved accuracy compared to measures reported in previous studies. ${ }^{10,11}$ 
EUS-EG has been used for the diagnosis of various pancreatic diseases and prediction of clinical course. EUS-EG provides more objective information than Rosemont classification for the endoscopic diagnosis of chronic pancreatitis. ${ }^{12}$ Confirming the degree of pancreatic fibrosis through the SR value helped determine the probability of exocrine insufficiency in patients with $\mathrm{CP} .{ }^{13}$ Additionally, measuring tissue hardness can be helpful in the differential diagnosis between hypervascular lesions, pancreatic neuroendocrine tumors, and metastatic malignant lesions. ${ }^{14}$ Strain elastography has also been used to estimate the risk of fistula formation after pancreatic surgery. ${ }^{15-17}$

As mentioned above, various efforts continue to improve the diagnostic accuracy of EUS for the differential diagnosis of SPL through elastography. Qualitative elastography, based on the color pattern of SPL, was mainly used for differential diagnosis in the early period. In the qualitative method, the stiffness of SPL was assessed by color predominance and distribution (homo- or heterogeneity). ${ }^{18,19}$ Qualitative EUS showed a relatively high sensitivity for the diagnosis of malignant SPLs but is a subjective evaluation method. Therefore, there may be inter-observer disagreement. ${ }^{20,21}$ To compensate for the shortcomings of the qualitative method, more objective semi-quantitative methods, such as SR and strain histogram, have been used. $6,11,22,23$

Semi-quantitative methods express SPL stiffness as an SR value or a mean histogram value. Previous studies using semi-quantitative EUS-EG showed that the SR value of a malignant mass was higher than that of an MFP and could be helpful in the differential diagnosis. ${ }^{10,11}$ In these studies, an optimal cut-off value for differential diagnosis had also been proposed, but there was a limitation in that external validation was not performed in a population other than patients who were investigated. We investigated whether the cut-off values presented in other studies showed high accuracy as well in our patients and noted that sensitivity, specificity, and accuracy were inferior compared to results from our cut-off value. In one study, 6.04 was presented as a cut-off value and showed $96.0 \%$ of accuracy for the differential diagnosis between PDAC and inflammatory mass. ${ }^{10}$ Another study presented 4.65 as their value, with an $86.5 \%$ accuracy. ${ }^{11}$ However, in this study population, their accuracy was only $52.27 \%$ each when their cutoff points were used (Table 4). In previous studies, it is thought that it was difficult to compare MFP and PDAC effectively because a relatively small number of patients with benign disease was included. To find an optimal cut-off value, additional research is needed to confirm whether the cut-off values presented in various studies have utility in other population groups as well.

However, there are still limitations when using EUS-EG for differential diagnosis. It is not easy to obtain a stable image lasting more than 5 seconds due to persistent patient breathing and normal bowel movements. The SR value, calculated by B/A, can be changed greatly even a small change in A, a strain value of ROI. If the degree of fibrosis inside the SPL is heterogeneous, it may be difficult to obtain a consistent SR value even through repeated measurements. In the present study, to overcome these limitations, the ROI was selected as a section that was large as possible in order to reflect the characteristics of the entire mass, sufficient time was spent for stable measurement of strain values, and the average of the more than three strain values was used. 
Recently, a new method of elastography, which provides absolute tissue hardness through shear-wave velocity rather than $\mathrm{SR}$, was introduced. However, this also has limitations, with further requirement for validation. ${ }^{24}$ Finally, EUS-EG is still an adjunctive method and is not a confirmatory diagnostic modality. There is thus, a limit to merely providing auxiliary information.

This study had several limitations. First, when compared to MFP and PDAC patients, relatively small numbers of PNEN patients were investigated. Due to a lack of PNEN patients, the optimal cut-off value for differential diagnosis between the three groups could not be suggested. The incidence of PNEN is relatively low, and the patients suspected of having a small-sized PNEN are often followed up using only imaging tests without a pathological diagnosis. Therefore, we subsequently investigated limited numbers of PNEN patients. Second, this study had a retrospective nature and was conducted by a small number of endosonographers. Therefore, a large-scale study conducted by a large number of endosonographers in a multicenter is needed to suggest universal findings. It is necessary to check whether there are differences depending on the echoendoscope and processor and whether our results were not influenced by the interference of the adjacent organs according to the location of the SPL. Despite these limitations, a strength of this study was that it was a well-organized study that investigated the cut-off SR value for differential diagnosis of SPL. This study presented relatively reliable data that suggested a cut-off score after propensity score matching in a large number of PDAC and MFP patients.

In conclusion, we provided the SR values of various SPLs through a large, retrospective study investigating quantitative EUS-EG. Moreover, we suggested optimal cut-off values for differential diagnosis between MFP and PDAC. Although tissue acquisition is essential for confirmative diagnosis, EUS-EG can provide helpful information in these cases.

\section{Methods}

\section{Study design}

This study was conducted as a retrospective investigation of patients who underwent EUS with strain elastography to evaluate SPLs. Patients were divided into three groups based on their diagnosis. Patient demographics, location and size of the SPL, and characteristics of EUS-SE were compared between groups.

A final diagnosis was made based on the pathology results of a biopsy or surgical specimen. Among patients in whom a confirmed diagnosis could not be obtained through biopsy or surgery, imaging studies were conducted 6 months after the endoscopic procedure. In cases wherein lesion progression or metastasis was observed on follow-up imaging, malignancy was considered confirmed. Benign disease was considered as confirmed in cases with a stable lesion without increasing size or metastasis. The histopathology of PEN was classified according to the WHO classification. ${ }^{25}$

\section{Patients}


We established a prospective registry of patients with pancreatobiliary disease who underwent endoscopic retrograde cholangiopancreatography or EUS from July 2016 onwards. We collected data to verify the effectiveness of procedures and identify predictors of complications (clinical trial registration at https://cris.nih.go.kr/cris: KCT0002082). Among the patients registered, those who underwent EUS-EG for SPL evaluation between July 2016 and June 2019 were retrospectively investigated. The inclusion criteria were as follows: (1) age $\geq 18$ years; and (2) presence of an SPL involving the pancreas, confirmed by at least one imaging modality. Patients who had pancreatic cystic lesions and those whose diagnosis had not been confirmed pathologically were excluded. All eligible patients were selected from the registry.

Patients were divided into three groups based on their diagnosis; pancreatic neuroendocrine neoplasm (PNEN group), mass-forming pancreatitis, including chronic pancreatitis and autoimmune pancreatitis (MFP group), and pancreatic ductal adenocarcinoma (PDAC group). Written informed consent was obtained from all patients. This study was approved by the Institutional Review Board of Gachon University Gil Medical Center (GCIRB2016-188) and was conducted in accordance with the principles set forth by the Declaration of Helsinki.

\section{Endoscopic ultrasound elastography}

EUS-EG were performed by experienced endosonographers (JH Cho, EJ Kim, and YS Kim) using a radial or linear echoendoscope (EG-3670URK, EG-3870UTK; Pentax Medical, Tokyo, Japan) with an ultrasound processor including the EG module (HI VISION Preirus; Hitachi Aloka Medical, Tokyo, Japan).

EUS-EG were performed according to our institution's standard protocol as described in our previous study. ${ }^{9}$ All endoscopies were performed under conscious sedation with intravenous midazolam and propofol. SPLs were identified by B-mode EUS at frequency of $7.5 \mathrm{MHz}$. The probe was maneuvered to the gastrointestinal lumen to deliver the strain to SPL. For assessment of elastography, different stiffness values were marked with various colors resulting in different elastographic patterns, which were shown as superimposed on conventional B-mode EUS images. The ROI for the elastographic evaluation was manually chosen so that the entire target and surrounding lesions were encompassed. A stable image of at least 5 -second duration was used to perform quantitative analysis and to define final pattern. Two different areas, $A$ and $B$, were selected. Area A was chosen as the largest possible area of an SPL. Area B was chosen as a soft (red) peripancreatic area, corresponding to the normal surrounding gut wall. The quotient $B / A$ was set as the strain SR of elastographic assessment (Figure 1A-C). To minimize selection bias, stiffness values were calculated thrice for all patients. The SR mean value of these calculations was then used for the analysis. The elastographic pattern was also defined qualitatively based on the predominant color present and the color distribution.

\section{Study Outcomes and Statistical Analysis}

The primary endpoint was to investigate the optimal cut-off SR value for differential diagnosis in SPL. Continuous variables were expressed as mean \pm standard deviation. Categorical variables are expressed as number and percentage. Multinomial logistic regression was performed to identify independent variables that showed significant differences between groups. Propensity score matching was performed using age 
and sex to eliminate differences in clinicopathological factors between MFP and PDAC. Paired t-tests were performed to compare the continuous variables and McNemar's test for categorical variables. P-values with $<0.05$ were considered statistically significant.

Youden's index is used to select the optimum cut-off point based on strain ratio for the diagnostic accuracy of quantitative EUS-EG. Sensitivity, specificity, positive predictive value, negative predictive value, and accuracy for quantitative EUS-SE were calculated with 95\% confidence intervals (Cls). The cut-off values providing accuracy of quantitative elastography based on previous studies were used to calculate these, as well as the corresponding cut-offs that stemmed from the present study. All statistical analyzes were performed using SAS version 9.4 (SAS Institute, Cary, NC, USA). All authors had access to the study data and reviewed and approved the final manuscript.

\section{Declarations}

\section{Acknowledgements}

This research was supported by a grant of the Korea Health Technology R\&D Project through the Korea Health Industry Development Institute (KHIDI), funded by the Ministry of Health \& Welfare, Republic of Korea (grant number : HI19C0481, HC21C0016)

\section{Authors' Contributions}

CIR analyzed and interpreted data and wrote the paper; JSH and $\mathrm{K} \mathrm{H}$, performed the data analysis; KEJ and KYS performed the endoscopy and interpreted the endoscopic findings; JS interpreted data and performed the statistical analysis; CJH performed the endoscopy, interpreted data, designed and supervised the study.

\section{Conflicts of interests and funding information}

The funder of this study (the Ministry of Health \& Welfare, R.O.K) has no financial relationship to gain or lose through this publication. The funder supported the cost of data collection, data analysis, and publication. All authors disclose that there are no funding or conflicts of interest with regard to this study except grant support mentioned above.

\section{Availability of Data and Materials}

The datasets generated and/or analysed during the current study are not publicly available because they contain potentially identifying patient data (restricted by the Institutional Review Board), but are available from the corresponding author on reasonable request by qualified, interested researchers.

\section{References}

1. Yoshinaga, S., Suzuki, H., Oda, I. \& Saito, Y. Role of endoscopic ultrasound-guided fine needle aspiration (EUS-FNA) for diagnosis of solid pancreatic masses. Dig Endosc 23 Suppl 1, 29-33. https://doi.org/10.1111/j.1443-1661.2011.01112.x (2011). 
2. Eloubeidi, M. A., Tamhane, A., Varadarajulu, S. \& Wilcox, C. M. Frequency of major complications after EUS-guided FNA of solid pancreatic masses: a prospective evaluation. Gastrointest Endosc 63, 622629. https://doi.org/10.1016/j.gie.2005.05.024 (2006).

3. Kitano, M. et al. Characterization of small solid tumors in the pancreas: the value of contrast-enhanced harmonic endoscopic ultrasonography. Am J Gastroenterol 107, 303-310. https://doi.org/10.1038/ajg.2011.354 (2012).

4. Iglesias-Garcia, J., Lindkvist, B., Larino-Noia, J., Abdulkader-Nallib, I. \& Dominguez-Munoz, J. E. Differential diagnosis of solid pancreatic masses: contrast-enhanced harmonic (CEH-EUS), quantitative-elastography (QE-EUS), or both? United European Gastroenterol J 5, 236-246. https://doi.org/10.1177/2050640616640635 (2017).

5. Cho, I. R. et al. Comparison of contrast-enhanced versus conventional EUS-guided FNA/fine-needle biopsy in diagnosis of solid pancreatic lesions: a randomized controlled trial. Gastrointest Endosc 94, 303-310. https://doi.org/10.1016/j.gie.2021.01.018 (2021).

6. Dietrich, C. F. \& Hocke, M. Elastography of the Pancreas, Current View. Clin Endosc 52, 533-540. https://doi.org/10.5946/ce.2018.156 (2019).

7. Kuwahara, T., Hara, K., Mizuno, N., Haba, S. \& Okuno, N. Present status of ultrasound elastography for the diagnosis of pancreatic tumors: review of the literature. J Med Ultrason (2001) 47, 413-420. https://doi.org/10.1007/s10396-020-01026-6 (2020).

8. Itokawa, F. et al. EUS elastography combined with the strain ratio of tissue elasticity for diagnosis of solid pancreatic masses. J Gastroenterol 46, 843-853. https://doi.org/10.1007/s00535-011-0399-5 (2011).

9. Kim, S. Y. et al. Diagnostic efficacy of quantitative endoscopic ultrasound elastography for differentiating pancreatic disease. J Gastroenterol Hepatol 32, 1115-1122. https://doi.org/10.1111/jgh.13649 (2017).

10. Iglesias-Garcia, J., Larino-Noia, J., Abdulkader, I., Forteza, J. \& Dominguez-Munoz, J. E. Quantitative Endoscopic Ultrasound Elastography: An Accurate Method for the Differentiation of Solid Pancreatic Masses. Gastroenterology 139, 1172-1180. https://doi.org/10.1053/j.gastro.2010.06.059 (2010).

11. Dawwas, M. F., Taha, H., Leeds, J. S., Nayar, M. K. \& Oppong, K. W. Diagnostic accuracy of quantitative EUS elastography for discriminating malignant from benign solid pancreatic masses: a prospective, single-center study. Gastrointest Endosc 76, 953-961. https://doi.org/10.1016/j.gie.2012.05.034 (2012).

12. Kuwahara, T. et al. Quantitative diagnosis of chronic pancreatitis using EUS elastography. J Gastroenterol 52, 868-874. https://doi.org/10.1007/s00535-016-1296-8 (2017).

13. Dominguez-Munoz, J. E., Iglesias-Garcia, J., Castineira Alvarino, M., Luaces Regueira, M. \& Larino-Noia, J. EUS elastography to predict pancreatic exocrine insufficiency in patients with chronic pancreatitis. Gastrointest Endosc 81, 136-142. https://doi.org/10.1016/j.gie.2014.06.040 (2015).

14. Kataoka, K. et al. Differentiation between pancreatic metastases from renal cell carcinoma and pancreatic neuroendocrine neoplasm using endoscopic ultrasound. Pancreatology. https://doi.org/10.1016/j.pan.2021.07.001 (2021). 
15. Hatano, M. et al. Quantification of pancreatic stiffness on intraoperative ultrasound elastography and evaluation of its relationship with postoperative pancreatic fistula. Int Surg 100, 497-502. https://doi.org/10.9738/INTSURG-D-14-00040.1 (2015).

16. Harada, N. et al. Preoperative Pancreatic Stiffness by Real-time Tissue Elastography to Predict Pancreatic Fistula After Pancreaticoduodenectomy. Anticancer Res 37, 1909-1915. https://doi.org/10.21873/anticanres.11529 (2017).

17. Kuwahara, T. et al. Usefulness of endoscopic ultrasonography-elastography as a predictive tool for the occurrence of pancreatic fistula after pancreatoduodenectomy. J Hepatobiliary Pancreat Sci 24, 649656. https://doi.org/10.1002/jhbp.514 (2017).

18. Janssen, J., Schlorer, E. \& Greiner, L. EUS elastography of the pancreas: feasibility and pattern description of the normal pancreas, chronic pancreatitis, and focal pancreatic lesions. Gastrointest Endosc 65, 971-978. https://doi.org/10.1016/j.gie.2006.12.057 (2007).

19. Giovannini, M. et al. Endoscopic ultrasound elastography for evaluation of lymph nodes and pancreatic masses: a multicenter study. World J Gastroenterol 15, 1587-1593. https://doi.org/10.3748/wjg.15.1587 (2009).

20. Mei, M., Ni, J., Liu, D., Jin, P. \& Sun, L. EUS elastography for diagnosis of solid pancreatic masses: a meta-analysis. Gastrointest Endosc 77, 578-589. https://doi.org/10.1016/j.gie.2012.09.035 (2013).

21. Ying, L. et al. Clinical utility of endoscopic ultrasound elastography for identification of malignant pancreatic masses: a meta-analysis. J Gastroenterol Hepatol 28, 1434-1443. https://doi.org/10.1111/jgh.12292 (2013).

22. Altonbary, A. Y., Hakim, H. \& El-Shamy, A. M. Diagnostic Efficacy of Endoscopic Ultrasound Elastography in Differentiating Solid Pancreatic Lesions: A Single-Center Experience. Clin Endosc 52, 360-364. https://doi.org/10.5946/ce.2018.160 (2019).

23. Costache, M. I. et al. Clinical impact of strain histogram EUS elastography and contrast-enhanced EUS for the differential diagnosis of focal pancreatic masses: A prospective multicentric study. Endosc Ultrasound 9, 116-121. https://doi.org/10.4103/eus.eus_69_19 (2020).

24. Ohno, E. et al. Diagnostic performance of endoscopic ultrasonography-guided elastography for solid pancreatic lesions: Shear-wave measurements versus strain elastography with histogram analysis. Dig Endosc 33, 629-638. https://doi.org/10.1111/den.13791 (2021).

25. Klimstra DS, K. G., La Rosa S, Rindi G. Digestive System Tumours in WHO Classification of Tumours. 5th edition: IARC, Lyon.

\section{Figures}



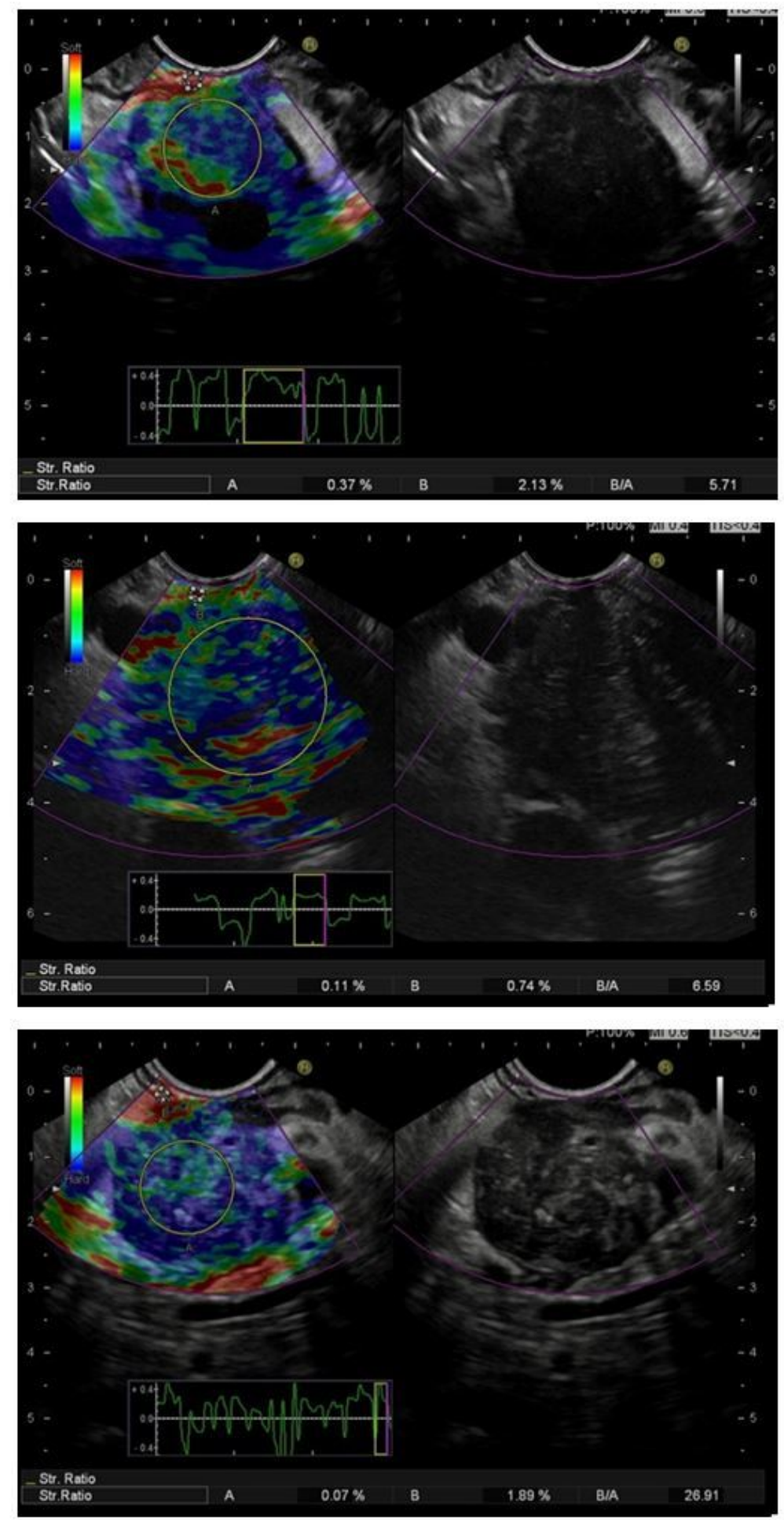

\section{Figure 1}

Endoscopic ultrasonography elastography measurements of the pancreas in mass forming pancreatitis (MFP), pancreatic neuroendocrine neoplasm (PNEN) and pancreatic ductal adenocarcinoma (PDAC) group patient. (a) MFP patient; strain ratio of 5.71. (b) PNEN patient; strain ratio of 6.59. (c) PDAC patient; strain ratio of 26.91. 


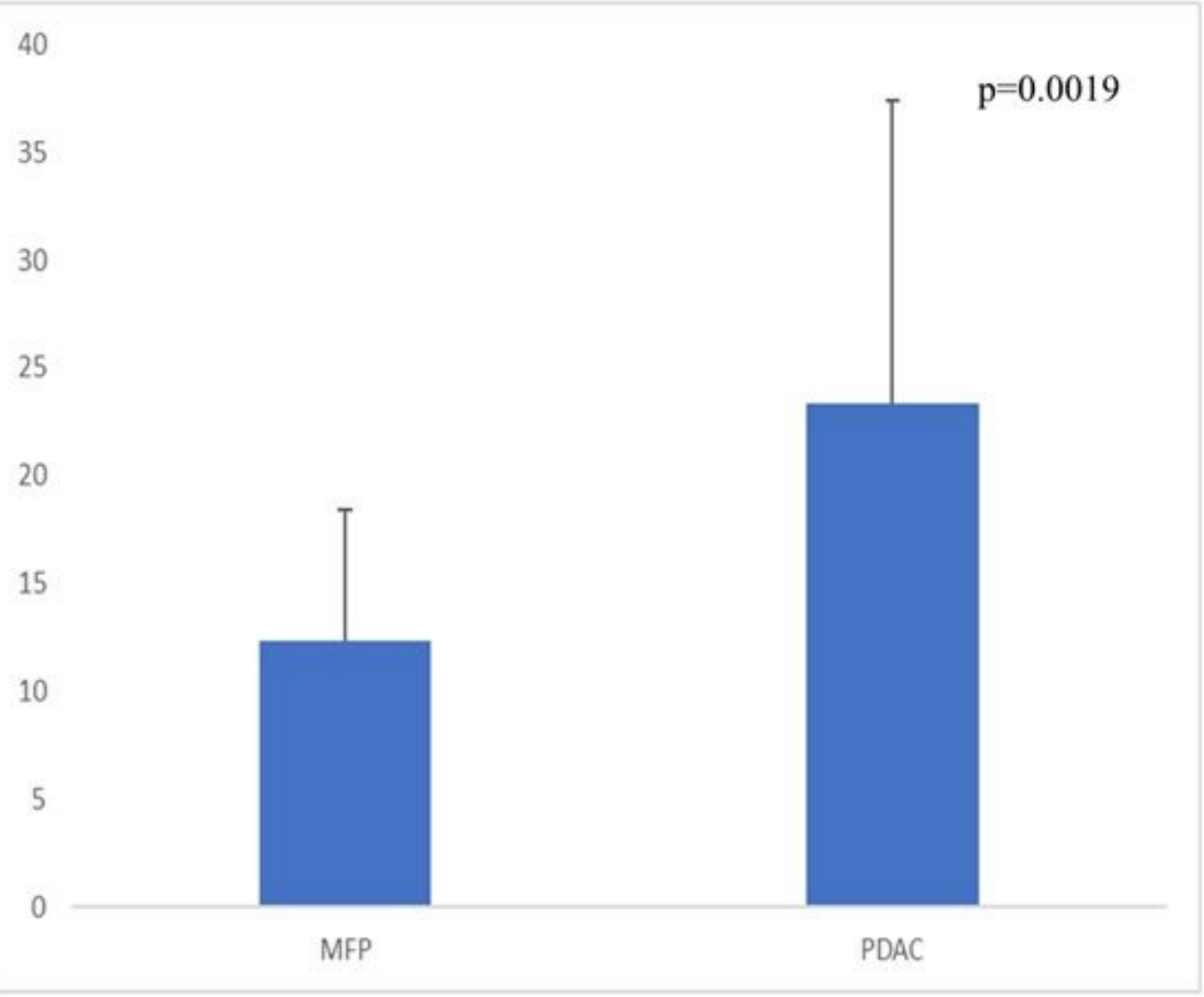

Figure 2

Comparison of strain ratio between MFP and PDAC. The mean strain ratio for MFP and PDAC were 12.33 and 23.37, respectively $(P=0.0019)$. 


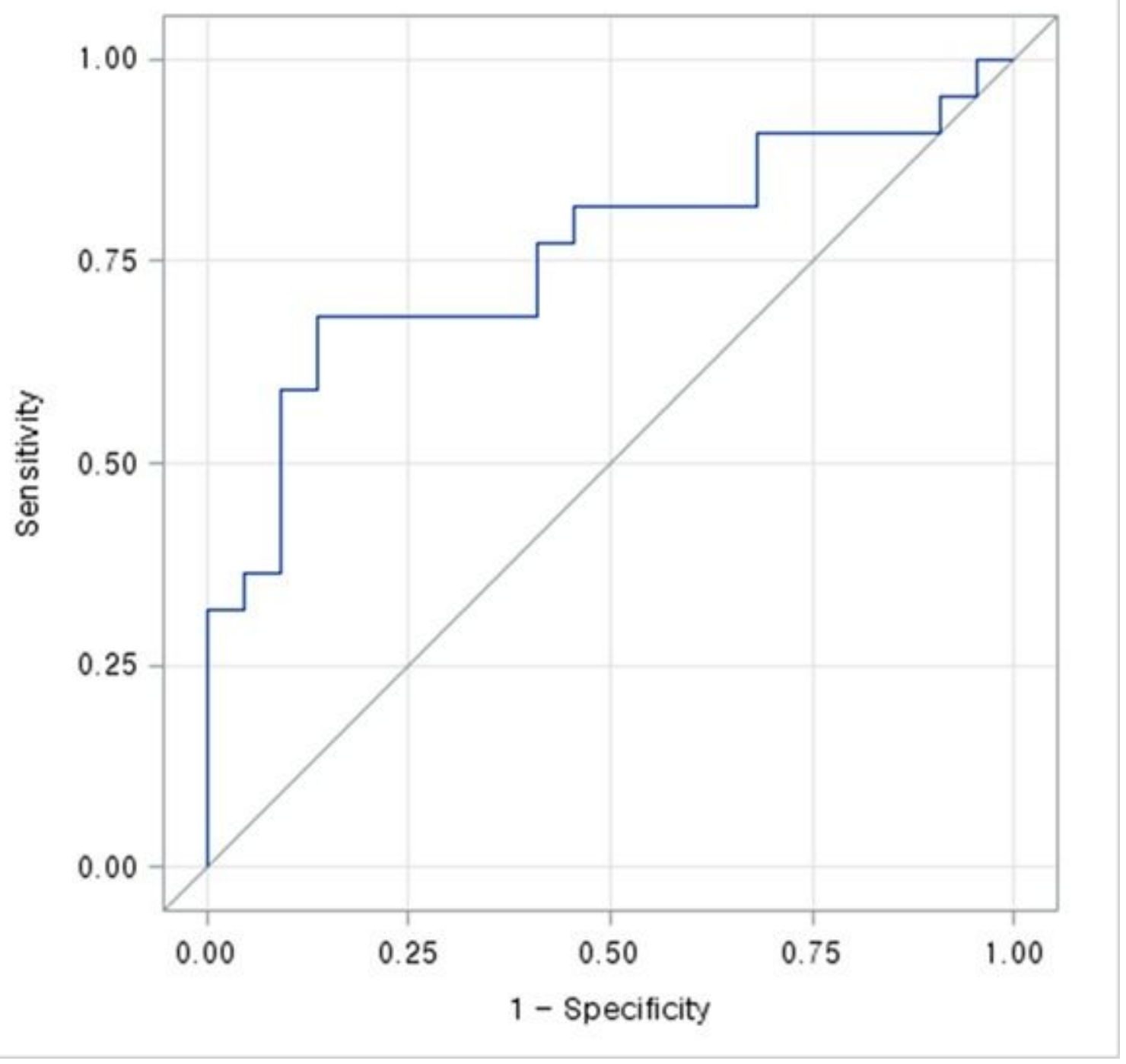

Figure 3

Receiver operating characteristic curve analysis of the cut-off strain ratio value (17.14) for the detection of pancreatic adenocarcinoma. 